\title{
ABC success: evidence from ISO 9000 certified companies in Thailand
}

Phaithun Intakhan

Faculty of Management Science, Lampang Rajabhat University, Lampang, Thailand

\begin{abstract}
Purpose - The purpose of this paper is to examine the success of activity-based costing (ABC) implementation by confirmatory factor analysis of ISO 9000 certified companies in Thailand.

Design/methodology/approach - A structured questionnaire was used to collect data from key participants, accountant managers in ISO 9000 certified companies.

Findings - The study confirmed the six constructs for the sample of 102 key participants. The results indicated that $\mathrm{ABC}$ implementation success in the context of ISO 9000 certified companies in Thailand consists of upper-management support, $\mathrm{ABC}$ system training, non-accounting ownership, links to quality initiative, adequate resources, and links to performance evaluation.

Originality/value - The findings have significant implications for ISO 9000 certified companies which intend to adopt or implement $\mathrm{ABC}$. Past findings on $\mathrm{ABC}$ implementation success have a small-sample size so they are of limited usefulness. This research has a larger sample size and more carefully chosen participants and so the generalizations are more acceptable.
\end{abstract}

Keywords Thailand, ABC implementation success, ISO 9000

Paper type Research paper

\section{Introduction}

Information quality is important when conducting business, not only domestically but also globally. Accounting information helps managers make sound decisions, such as setting prices, measure performance, manage costs, and model costs and process improvements (Majid and Sulaiman, 2008; Smit et al., 2008). However, traditional costing is not timely, and may be inaccurate or too detailed, and this information overload may be harmful to decision making (Schick et al., 1990; Smit et al., 2008). The traditional accounting approach often uses a single or departmental base, allocating cost to objects or products, for example through labor hours, machine hours, and production units employed (Majid and Sulaiman, 2008) and it is therefore not appropriate for firms which have many products or services and these firms require a new costing method in order to allocate costs and monitor cost effectiveness (Foong and Teruki, 2009).

Activity-based costing (hereafter $\mathrm{ABC}$ ) is an innovative accounting method to allocate overheads and costs with a higher degree of accuracy and to assign costs to products and services according to the activities and resources consumed (Smit et al., 2008). ABC uses cost-drivers to allocate the costs of products and services (Banker et al., 2008). ABC not only improves the accuracy of product- and service-costing but also helps managers understand how resources are used through financial performance, such as return on investment and bottom line statements (Cagwin and Bouwman, 2002). Prior research on $\mathrm{ABC}$ has focussed on various aspects, including, for example the success of $\mathrm{ABC}$

(C) Phaithun Intakhan.

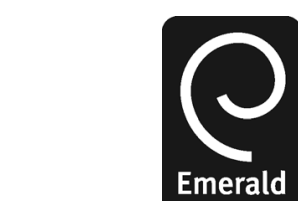

Asian Review of Accounting Vol. 22 No. 3, 2014

Emerald Group Publishing Limited $1321-7348$

DOI 10.1108/ARA-06-2013-0044 
ARA

22,3

288
(Anderson and Young, 1999; Foster and Swenson, 1997; Roberts and Silvester, 1996; Shields, 1995), ABC implementation (Gosselin, 1997; Krumwiede, 1998; Majid and Sulaiman, 2008; McGowan and Klammer, 1997; Chongruksut and Brooks, 2005), and the benefits and consequences of ABC (Ittner et al., 2002; Kennedy and Affleck-Graves, 2001; Swenson, 1995; Cagwin and Bouwman, 2002; Maiga and Jacobs, 2008). In this paper, we focus on $\mathrm{ABC}$ implementation success and factors influencing this. Past research identified two main factors affecting $\mathrm{ABC}$ success, namely technical and contextual, and behavioral and organizational variables. However, this paper focusses on contextual, behavioral and organizational variables because these are more strongly associated with ABC success than are technical variables (Shields, 1995). We use five significant constructs of the Shields (1995) model, namely top management support (TMS), ABC system training (AST), links to performance evaluation (LPE), links to quality initiatives (LIQ) and the adequacy of resources, along with one suggestion from Chongruksut and Brooks (2005), non-accounting ownership (NAO), to analyze ABC implementation success in the context of ISO 9000 certified companies in Thailand.

$\mathrm{ABC}$ implementation success refers to the degree to which management uses $\mathrm{ABC}$ information for decision making in order to improve financial performance (Foster and Swenson, 1997). This paper measures the success of $A B C$ by support for, and the convenience and benefits of, the ABC system (Anderson, 1995; Chongruksut and Brooks, 2005). The research used confirmatory factor analysis (CFA) in order to investigate the six behavioral and organizational constructs on $\mathrm{ABC}$ implementation success. This research collected data from ISO 9000 companies in Thailand because ISO 9000 and ABC support continuous improvement efforts in quality and productivity (Brimson and Antos, 2004; Larson and Kerr, 2007). Therefore, firms with ISO 9000 should apply ABC. In addition, there are many benefits accruing from ISO 9000 registration. These include, for example, giving customers confidence in the quality of the products and services, helping written management systems control effectively the business process life-cycle, ensuring that management can meet the needs of customers and reduce losses in operational quality and maintain cost savings. In Thailand, businesses that are ISO certified tend to have their customer base abroad, such as in the EU and USA, which emphasize quality systems. Thus, if businesses adopt $\mathrm{ABC}$ and so make accurate cost analysis, this can help to specify constraints and cut unnecessary costs. Businesses that are ISO certified should therefore use the $\mathrm{ABC}$ system because this involves a similar process. This is in agreement with Sayle (2005), who noted that $\mathrm{ABC}$ is a technique that enhances the work process and is in accord with ISO 9000. Furthermore, the research of Larson and Kerr (2007) recommended that ISO certification and ABC can work together by separating functional departments. $\mathrm{ABC}$ is typically implemented by accounting and finance sections and ISO is usually implemented by the quality group. In addition, sales and marketing is an important function linking data with finance, accounting, and manufacturing systems. Besides, the number of ISO 9000 companies is also expected to increase steadily; in Thailand, numbers have increased from 1,835 in 2012 to 2,351 in 2013. This research is thus useful for companies entering the ISO system and adopting the $\mathrm{ABC}$. Here, the key research question is to confirm the six constructs (topmanagement support, NAO, adequate resources (ADE), LPE, AST, and LIQs), and whether these match the models of Shields (1995) and Chongruksut and Brooks (2005) in the context of companies that are ISO 9000 certified and which apply ABC.

This research makes several important contributions. It is the first known examination of $\mathrm{ABC}$ implementation success in the context of ISO 9000 companies. Second, it focusses only on behavioral and organizational variables which are strongly 
associated with $\mathrm{ABC}$ success. Finally, there is very little prior research on the success of $\mathrm{ABC}$ implementation in Thailand. This study is structured as follows. The relevant literature on all six constructs is reviewed. Next, the research methods used to test the CFA are discussed and lastly come the results, a discussion on the findings and the conclusion.

\section{Literature review}

In this study, TMS, NAO, adequacy of resources, links to performance measurements, AST, and LIQs are related to the success of ABC implementation in ISO 9000 certified companies in Thailand. To investigate the stability of the relationship between evaluations of $\mathrm{ABC}$ implementation success and these factors, a conceptual model is presented involving the CFA of ABC success of ISO certified companies in Thailand, as shown in Figure 1.

This model is combined with two academic sources: Shields (1995), who was the first to explore contextual, organizational, and behavioral factors associated with $\mathrm{ABC}$ success, and Chongruksut and Brooks (2005), who studied ABC adoption and success in Thailand. They ranked five factors affecting $\mathrm{ABC}$ implementation success, including TMS and commitment, clear and concise objectives, and non-accounting commitment and ownership. This paper investigates the clarity of the objectives of upper-management because, given the nature of Thai society, the effectiveness of these objectives, and the degree to which they are met depends on management (Morakul and $\mathrm{Wu}, 2001$ ) and hence, we use the concept of NAO to measure $\mathrm{ABC}$ implementation success.

\subsection{Why ABC implementation success is important for companies that emphasize on quality}

ISO 9000 is a basic principle of quality management systems consisting of five processes: process mapping, documentation, performance, audit, and corrective action (Larson and Kerr, 2007). A quality system is a set of management activities by which company efficiency is improved through factors such as quality improvement and cost reduction. ISO 9000 can help firms establish the agenda required for effective and efficient quality assurance and quality management systems (Bhuiyan and Alam, 2005). The benefits accruing to ISO qualification for companies may be separated into internal and external. The internal benefits are that employees gain a better understanding of work processes and responsibilities as well an awareness of quality-improvement culture through teamwork, management support and participation, and better optimization of resources (Mcdonald et al., 2003; Chin et al., 2000; Santos and Escanciano, 2002). The external benefits are improved market and company reputation, higher perceived quality, cost reduction, and customer service improvement (Larson and Kerr, 2002;

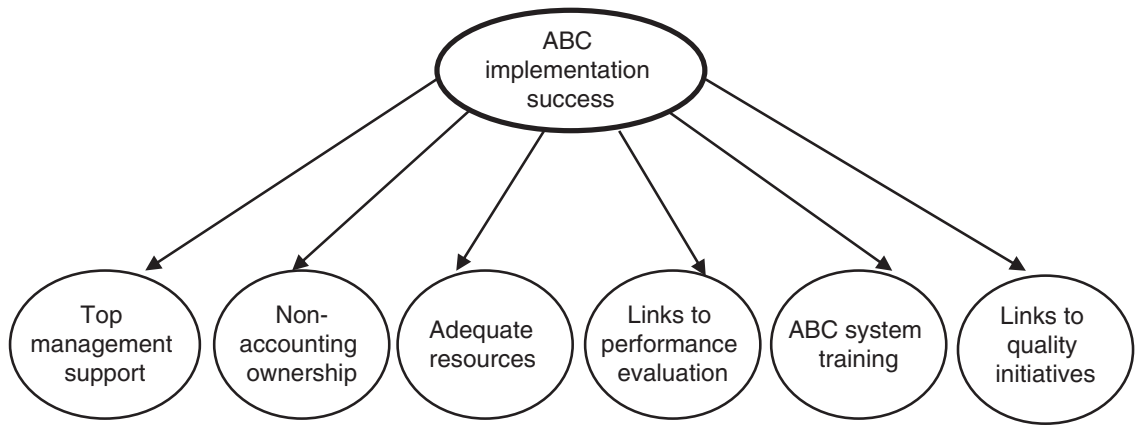

ISO 9000 certified companies in Thailand

289 
ARA

22,3

290
Brack, 1999; Bhuiyan and Alam, 2005). ABC ties overhead cost and direct costs to specific products, services or customers by activity, and also highlights the activities of the companies as well as using cost drivers as an important instrument to allocate costs. Firms with $\mathrm{ABC}$ implementation success are more likely to have accurate product and service costs, cost control improvements, and to eliminate waste by providing unnecessary non-added activities. Hence, $\mathrm{ABC}$ information can support managers when establishing cost reduction programs and can also help firms manage activities focussed on decreasing costs and increasing quality. Costs can be decreased by reducing unnecessary expenditure, and reducing the time taken to produce products and services. Quality can also be increased by more efficient planning of production activities and material handling, quicker delivery, and reducing waste. In addition, prior research shows that the many steps involved in successful ISO 9000 registration are also required to implement $\mathrm{ABC}$, including items such as $\mathrm{ABC}$ implementation of linking activities to objects, when the results will be used in the process of ISO 9000 evaluation (Larson and Kerr, 2002). Moreover, ABC and ISO are similar in the way that they focus on documentation and managing activities. In conclusion, successful $\mathrm{ABC}$ implementation not only gives information on costs and processes but also assists firms in emphasizing quality.

\subsection{ABC in Thailand}

There has been limited research focussing on $\mathrm{ABC}$ success in Thai organizations. However, Chongruksut and Brooks (2005) surveyed 292 listed companies in the Bangkok region regarding issues associated with $\mathrm{ABC}$ adoption and implementation. They found that 14 (35.65 percent) of the firms had adopted $\mathrm{ABC}$ and that the rate of $\mathrm{ABC}$ adoption in Thailand was relatively high compared to other Asian countries. Organizations with a larger range of products and with a higher intensity of capital equipment were more likely to adopt $\mathrm{ABC}$. Moreover, the researchers explained that upper-management support and the clarity of the objectives of the $\mathrm{ABC}$ implementation among $\mathrm{ABC}$ designers and users were the most important factors determining the success of ABC implementation. In addition, Tupmongkol (2008) showed that nine main factors including TMS, computer systems, education and training, the $\mathrm{ABC}$ team, the objectives of $\mathrm{ABC}$ implementation, the $\mathrm{ABC}$ implementation process, the benefits of $\mathrm{ABC}$ implementation, problems with $\mathrm{ABC}$ implementation, and the level of progress of $\mathrm{ABC}$ implementation influenced the success of ABC. Morakul and $\mathrm{Wu}$ (2001), who studied the relationship between culture and $\mathrm{ABC}$ implementation, found that the key factor determining the failure of $\mathrm{ABC}$ was the high-power distance in Thai society, which led to accountants being afraid of losing their power. The above studies focussed on company adoption and implementation but had the limitation of small sample sizes. This study extends the work in these areas, particularly with regard to the success of ISO 9000 certified firms in Thailand because ISO 9000 supports continuous improvement efforts in quality and productivity so that firms with ISO 9000 should apply ABC and this leads to the research having a larger sample size.

\subsection{Measurement of $A B C$ implementation success}

Ways of assessing $\mathrm{ABC}$ implementation success can be divided into two categories; first, the overall success level and second, the attainment of a particular stage of implementation. The main purpose of measuring overall success is that the meaning of success was problematic and past literature was not clear about this meant. Several authors have used this idea, including Shields (1995), who measured overall success 
through two questions: first, "Overall, how successful do you believe the $\mathrm{ABC}$ initiative in your firm has been?" second, "Whether financial benefits had or had not resulted from ABC?" Anderson and Young (1999) measured the overall success of the ABC system, but substituting for "overall value of $\mathrm{ABC}$," "perceived accuracy of $\mathrm{ABC}$ data," and "perceived use of ABC data." Chongruksut and Brooks (2005) asking participants to rate perceptions of the success of implementation of $\mathrm{ABC}$ in their firms and divided in to five level; "very poor," "poor," "average," "good," and "very good." To measure particular stages of implementation, Anderson (1995) said that successful measurement of implementation of $\mathrm{ABC}$ was a multidimensional composite measure. Foster and Swenson (1997) measured the success of the ABC dimensions by using a variety of tools consisting of measurements based on the use of ABCM information in decision making, measurements based on decisions taken with ABCM information, measurements based on the dollar improvements resulting from $\mathrm{ABCM}$ and measurements based on management evaluation on the overall success of ABCM. Moreover, Gosselin (1997) has identified three levels of ABC including AA "to identify the activity," ACA "to identify the costs of each activity," and ABC "to trace costs of products and services." Research measuring the success of $\mathrm{ABC}$ prefer multidimensional measures. For example, Baird et al. (2004) used Gosselin's (1997) and Byrne's (2011) success model to measure the success of $\mathrm{ABC}$ implementation. This was divided into user attitude, technical characteristics, perceived usefulness in improving user job performance, and organizational process.

In Thailand, research involving $\mathrm{ABC}$ is relatively rare because Thailand is a developing country and the rate of adaptation of modern accounting management techniques is limited. Chongruksut and Brooks (2005) found only 14 companies that had implemented the ABC system, and the research of Tupmongkol (2008) and Morakul and Wu (2001) were limited to case studies. To ensure the appropriate population group, this research measures the success of the costing system activity by asking participants to rate perceptions of the success of implementation of $\mathrm{ABC}$ in their firms, which is similar to Chongruksut and Brooks (2005). This was divided into five levels: "very poor," "poor," "average," "good," and "very good." Totally, 13 companies answered "very good," 32 "good" and 57 "average."

\subsection{TMS}

This refers to the degree of visible support from senior or top managers for ABC (Anderson and Young, 1999). Prior research mentioned that this is a significant factor affecting the success of ABC implementation (Anderson and Young, 1999; Chongruksut and Brooks, 2005). This support is important when using information from $\mathrm{ABC}$ systems to communicate with non-accounting staff in order to promote and support ABC (Shields, 1995). In addition, Majid and Sulaiman (2008) stated that a steering committee should oversee ABC implementation and should comprise top-level management in order to ensure that the staff committee was on the right track. Moreover, senior management should invest in and drive forward ABC projects by providing training and technology. Morakul and $\mathrm{Wu}$ (2001) indicated that Thai society had a high-power-distance culture so top managers in Thai companies are those who have power to take action and make final decisions in the firm and therefore they play an important role in monitoring $\mathrm{ABC}$ project success.

\section{$2.5 \mathrm{LPE}$}

According to past research, LPE are important in determining the success of ABC implementation (Shields and Young, 1989; McGowan and Klammer, 1997; Cagwin and Bouwman, 2002). This factor refers to the degree to which firms increase compensation
ISO 9000 certified companies in Thailand

291 
ARA

22,3

292 such as bonuses, promotions, and other financial rewards in relation to the quality of the $\mathrm{ABC}$ system. Performance measures consist of setting targets and comparing outcomes with goals and these may be simple or complex indicators, such as the economy, efficiency, or effectiveness (Amir, 2011). These affect job outcomes and organization performance. To link ABC to performance evaluation, Majid and Sulaiman (2008) argued for comparison with actual costs resulting from $\mathrm{ABC}$ and internal information, such as last year's numbers, target costs set and external information, such as competitors' costs. When firms link $\mathrm{ABC}$ systems and performance measurement through compensation, bonuses and other company benefits, the workforce tends to feel that $\mathrm{ABC}$ is important and this builds motivation and leads to ABC success (Shields and McEwen, 1996).

\subsection{AST}

AST refers to the degree of training for designing, implementing and using $\mathrm{ABC}$ (Cagwin and Bouwman, 2002). Training is necessary when adopting new systems, such as $\mathrm{ABC}$ and it is not only to educate staff on the reasons to adopt $\mathrm{ABC}$, but also to reduce resistance to it (Shields, 1995). For design-state training, it is necessary to help employees understand the technical aspects of $\mathrm{ABC}$, such as its design and the necessity of providing adequate computing resources (Anderson et al., 2002). Implementation-state training is also important because training improves the skill levels of employees in, for example, the use of software written by external consultants (Majid and Sulaiman, 2008). With regard to state training, this is essential because training helps staff select information to present to senior managers to assist in decision making. Past research confirms that training is important for ABC success. For example, Krumwiede (1998) found a highly significant relationship between $\mathrm{ABC}$ training programs and levels of success in implementing $\mathrm{ABC}$ and Shields (1995) stated that the training program affects the level of satisfaction with $\mathrm{ABC}$, which is one method to measure $\mathrm{ABC}$ success.

\subsection{NAO}

$\mathrm{ABC}$ is really a whole-firm project, not an accounting project; when $\mathrm{ABC}$ is owned by accountants, this increases the risk of failure and so NAO refers to the degree of commitment of groups or individuals (such as design engineers and operations staff) who are not accountants but who are involved in the ABC model (Chongruksut and Brooks, 2005). Morakul and Wu (2001) showed that Thai society involves a highpower distance so if only the accounting department are responsible for an ABC project, they may be afraid to lose the power which they hold through control of information important to other departments. $\mathrm{ABC}$ projects should therefore involve the entire company and require the participation of all parts of the organization. Cooper et al. (1992) stated that the main factor causing ABC delay is accountants being in sole control of an ABC project. Moreover, Maelah and Ibraim (2006) indicated that when non-accountants participate in the early stages of $A B C$ implementation, the project is more successful. NAO includes the commitment of people and groups in the company who are not accountants to using $\mathrm{ABC}$ information and this has consequences for senior management support, training and the linkage of $A B C$ to performance measurement. This induces employees to acknowledge and implement better the $\mathrm{ABC}$ system.

\section{$2.8 A D E$}

$\mathrm{An} \mathrm{ABC}$ project requires plentiful resources, including, for example an $\mathrm{ABC}$ team, software, hardware, time, and people (Majid and Sulaiman, 2008) so ADEs refers to the 
material and people needed to complete an $\mathrm{ABC}$ project successfully. Resources are needed for all states of $\mathrm{ABC}$. For example, the implementation state requires adequate funds in addition to understanding, knowledge, and skills. Prior research shows that this influences the success of ABC. Majid and Sulaiman (2008) argued that sourcing suitable ACB software affected ABC success, as did hiring external consultants with the purpose of training employee to use ABC software. Moreover, Krumwiede (1998) and Innes et al. (2000) indicated that system design, adoption, and implementation are all time consuming. In addition, firms with sufficient internal resources can reduce levels of resistance to ABC systems (Shields, 1995).

\section{$2.9 \mathrm{LIQ}$}

LIQ refers to the level of a company's commitment to improving the quality of all parts of an organization by using $\mathrm{ABC}$ information and other speed-initiative techniques. The ABC system is a tool providing more accurate and relevant information for company decision making. It is also thought of as a process management tool that is available to support continuous improvement efforts in quality (Larson and Kerr, 2007). Many researchers have argued that if companies can more closely integrate ABC systems and competitive strategy, this would increase the chances of success in developing ABC. Shields (1995) stated that companies could combine ABC with quality initiatives such as just-in-time, TQM, and other speed initiatives so that higher degrees of ABC success could be reached. Similarly, Shields and McEwen (1996) found that firm links between $\mathrm{ABC}$ success and quality initiatives is more likely to lead to $\mathrm{ABC}$ success. Likewise, Maiga and Jacobs (2008) linked ABC to cost, quality, and cycle-time improvements. The results showed that $\mathrm{ABC}$ has a significant positive association with quality improvements. In addition, Innes et al. (2000) stated that the success of $\mathrm{ABC}$ is related to quality management policies. In summary, $\mathrm{ABC}$ systems can help process management in the company when $\mathrm{ABC}$ is combined with quality initiative, especially just-in-time, TQM, and six-sigma.

\section{Research method}

\subsection{ISO 9000 certified companies in Thailand}

ISO 9000 is managed by the International Organization for Standardization, an international federation with members in over 130 countries (Larson and Kerr, 2007). It focusses on quality management and assurance and assists firms in successfully documenting quality systems and in their implantation and maintenance. ISO 9000 companies tend to be more profitable than non-ISO 9000 firms so many companies pursue this in order to control and reduce costs (Goodman, 1998). In Thailand, 1,835 companies in 64 industrial categories have so far adopted ISO 9000. The largest of the categories are metal products, wholesale and retail, tools and electrical equipment, transportation and support activities, and plastic products (http:// app.tisi.go.th/syscer/9000_t.html, accessed September 1, 2012).

The characteristics of the companies in this study are shown in Table I. The organizations in the sample are found in various industrial categories: metal products, wholesale and retail trade, electrical machinery, transport and related activities, plastic products, other chemical products, cement and concrete, basic chemicals, computer and related activities, construction, maintenance and repair of motor vehicles, rubber products, and motor vehicles and transport equipment. All have been in operation for more than 15 years, employ fewer than 300 staff and have successfully implemented ABC. Non-response bias is always a concern in survey 
Industry

Metal product $\quad 38$

Wholesale/retail trade $\quad 32$

Electrical machinery 25

$\begin{array}{ll}\text { Transport and supporting activities } & 21\end{array}$

$\begin{array}{ll}\text { Plastic product } & 14\end{array}$

Other chemical products $\quad 12$

Cement/concrete 10

Basic chemicals

Computer and related activities $\quad 8$

Construction $\quad 7$

Other 6

Years company has been established
One to five years

Five to ten years 21

$\begin{array}{ll}11-15 \text { years } & 50\end{array}$

Over 15 years $\quad 95$

Number of full-time employees
$1-300$

$300-600+51$

$601-900+21$

Over $900 \quad 19$

$A B C$ adoption and implementation

$\begin{array}{ll}\text { Table I. } & \text { Intention to adoption }\end{array}$

$\begin{array}{llr}\text { Sample characteristics } & \text { Implementation } & 102\end{array}$

research so to examine the likelihood of this, a comparison of mean scores between early and late respondents (first two weeks against second two weeks) on major constructs (i.e. TMS and NAO) was conducted by $t$-test. This revealed no significant differences and so we conclude that non-response bias is not a problem in this study (Armstrong and Overton, 1977).

\subsection{Sample selection and data collection procedure}

In this study, 900 companies with ISO 9000 were selected using probability sampling (simple random method). The key participants in this study were accounting managers. All items in the questionnaire were adopted from earlier research but all the originals were in English so to improve accuracy, these were translated into Thai and then two independent bilingual individuals back-translated. To confirm the measurement instrument and to guarantee the suitability of the survey administration methods, pre-tests of the questionnaire were conducted with 30 accountant managers. From the comments and findings obtained from this pre-test, a few modifications were made to clarify the language and the sequencing of several items was altered. Data were collected by using a mail survey. 900 questionnaires were sent to key participants for completion. Within eight weeks of mailing the questionnaires, 181 firms had replied 102 which had adopted $\mathrm{ABC}$ and this gave a 20.1 percent response rate. According to Smith (2003), such a response rate (i.e. $<25$ percent) is now common in accounting research and this rate is also considered adequate for statistical examination and the making of inferences. 
Measurement of the variables was governed by their utility in prior academic research. A combined measure of "TMS" was used in the research. Shields (1995) and Baird et al. (2007) hypothesized active support, effective communication of ABC in the company, and time and commitment of ABC as factors. Chongruksut and Brooks (2005) theorized that clear and shared objectives in $\mathrm{ABC}$ were important.

NAO were measured with a three-item scale consisting of items developed by Cagwin and Bouwman (2002) and Chongruksut and Brooks (2005). The items reflect cross-functional, non-accounting users of $\mathrm{ABC}$ information, and the sharing of $\mathrm{ABC}$ information between accountants and non-accountants.

ADEs was measured with a three-item scale consisting of items developed by Shields (1995) and adapted by Anderson and Young (1999). The items are adequate staff, information, and equipment and materials.

A four-item measure has been used for performance evaluation. High-performance $\mathrm{ABC}$ is recognized through rewards (financial or otherwise) and compensation designed to motivate staff to work toward $\mathrm{ABC}$ implementation, which were derived from the LPE. This measurement was developed by Anderson and Young (1999) and Chongruksut and Brooks (2005). Higher LPE scores suggest more firms link ABC to performance evaluation.

AST was measured with a four-item scale, including items developed by Shields (1995), Cagwin and Bouwman (2002), and Chongruksut and Brooks (2005). The items reflect factors such as training provided for design, implementation, and use of $\mathrm{ABC}$ and the trainings effectiveness.

A two-item scale, "combine $\mathrm{ABC}$ with quality initiative" and "firm commitment to quality improvement," was developed by Cagwin and Bouwman (2002), and Chongruksut and Brooks (2005). To assess the degree to which the "LIQ" has been achieved, its relation to process improvement and how far utilization of information will increase.

\subsection{Methods}

From the 181 the companies which responded, the researchers selected 102 which had adopted $\mathrm{ABC}$ system to analyze data. The items used for constructs were rated on five-point Likert scales, ranging from 1 (strongly disagree) to 5 (strongly agree). CFA was used to examine how well the 20 items of ABC success fitted the six constructs and is appropriate to the population. Maximum likelihood estimation was used to estimate model parameters. To assess the fit of the six constructs to these data, we chose eight indicators namely $\chi^{2}, \mathrm{CMIN} / \mathrm{df}$, adjusted goodness of fit index (AGFI), incremental fit index (IFI), comparative fit index (CFI), normed-fit index (NFI), root mean residual (RMR), and root mean square error of approximation (RMSEA) to determine model fit: CMIN/df $<3, \chi^{2} p>0.05$, RMSEA below 0.05, and RMSR below 0.05 (Diamantopoulos and Siguawl, 2000), AGFI above 0.80, CFI, IFI, and NFI above 0.90 (Bryne, 2001).

\section{Results}

The measurement properties of scale used in this study were evaluated by checking internal consistency, reliability, and discriminant validity. The item and construct descriptive statistics are shown in Table II. The internal reliability of construct items was tested by Cronbach's coefficient (0 which ranged from 0.833 to 0.912 . All values were above the minimum acceptable level of 0.70 , as recommended by Nunnally and Bernstein (1994). The standard factor loadings for all items were high and statistically significant $(p<0.05)$ and shown in Figure 2. These ranged from 0.55 to 0.87 for the 
ARA

22,3

296
Constructs and items included

Upper management has provided time and commitment

to the $\mathrm{ABC}$ implementation effort

This company's top managers have provided active support

for $\mathrm{ABC}$ practice

Top management effectively communicated its support for

$\mathrm{ABC}$ system.

Top management has clear and concise objectives of $\mathrm{ABC}$ system and share to both designers and users

Non accounting ownership (NAO)

The non accounting (such as production/marketing groups and so on) are committed to use $\mathrm{ABC}$ information

The implementation team was cross-functional

The accountants have shared their ownership of

information with non-accountants

Adequate resource (ADE)

The people who developed the $\mathrm{ABC}$ model had access to the people from whom they needed to get information

The ABC development project was adequately staffed to insure completion of the task in the time allotted

The people who developed the $\mathrm{ABC}$ model had the

equipment and materials needed to do their job

Link to performance evaluation (LPE)

In this ABC model, high performance is recognized and rewarded

$\mathrm{ABC}$ data have been used for performance evaluation

Compensation systems in the company are designed to motive employees to implement $\mathrm{ABC}$

In this $\mathrm{ABC}$ model, financial rewards are tied directly to performance

ABC system training (AST)

Adequate training was provided for designing $\mathrm{ABC}$

Adequate training was provided for implementing $\mathrm{ABC}$

Adequate training was provided for using $\mathrm{ABC}$

Education from $\mathrm{ABC}$ training (such as software training)

was useful and can apply to $\mathrm{ABC}$ system.

Link to quality initiative (LIQ)

Firm combined $\mathrm{ABC}$ system with quality initiative (such as Just in time, TQM)

Table II.

Items and construct descriptive statistics
Firm commits to quality improvement through involvement and visibility in quality activities
Factor Cronbach's

\begin{tabular}{llll} 
loading & $\alpha$ & $\mathrm{CR}$ & AVE \\
\hline
\end{tabular}

$\begin{array}{lll}0.833 & 0.797 & 0.504\end{array}$

0.65

0.87

0.80

0.55

$\begin{array}{lll}0.903 & 0.748 & 0.499\end{array}$

0.80

0.92

0.90

0.85

$0.912 \quad 0.824 \quad 0.500$

0.87

0.90

$\begin{array}{lll}0.886 & 0.798 & 0.498\end{array}$

0.78

0.90

0.81

0.76

0.82

0.81

0.79

0.86

$\begin{array}{lll}0.826 & 0.788 & 0.501\end{array}$

0.88

0.82

TMS construct, from 0.80 to 0.89 for the NAO construct, from 0.85 to 0.90 for the ADE construct, from 0.76 to 0.90 for the LPE construct, from 0.79 to 0.86 for AST, and from 0.82 to 0.88 for LIQs. This indicates that the items are acceptable measures of their respective construct. Composite reliability (CR) and average variance extracted (AVE) were used to verify construct reliability. Values of the CR ranged from 0.748 to 0.824 , which are above the 0.60 threshold suggested by Bagozzi and Yi (2001). The AVE values ranged from 0.497 to 0.504. Although the AVE of NAO, LPE and AST are 0.499, 0.498, and 0.497 , respectively, on average, the overall mean of the AVE is 0.500 , which shows that 


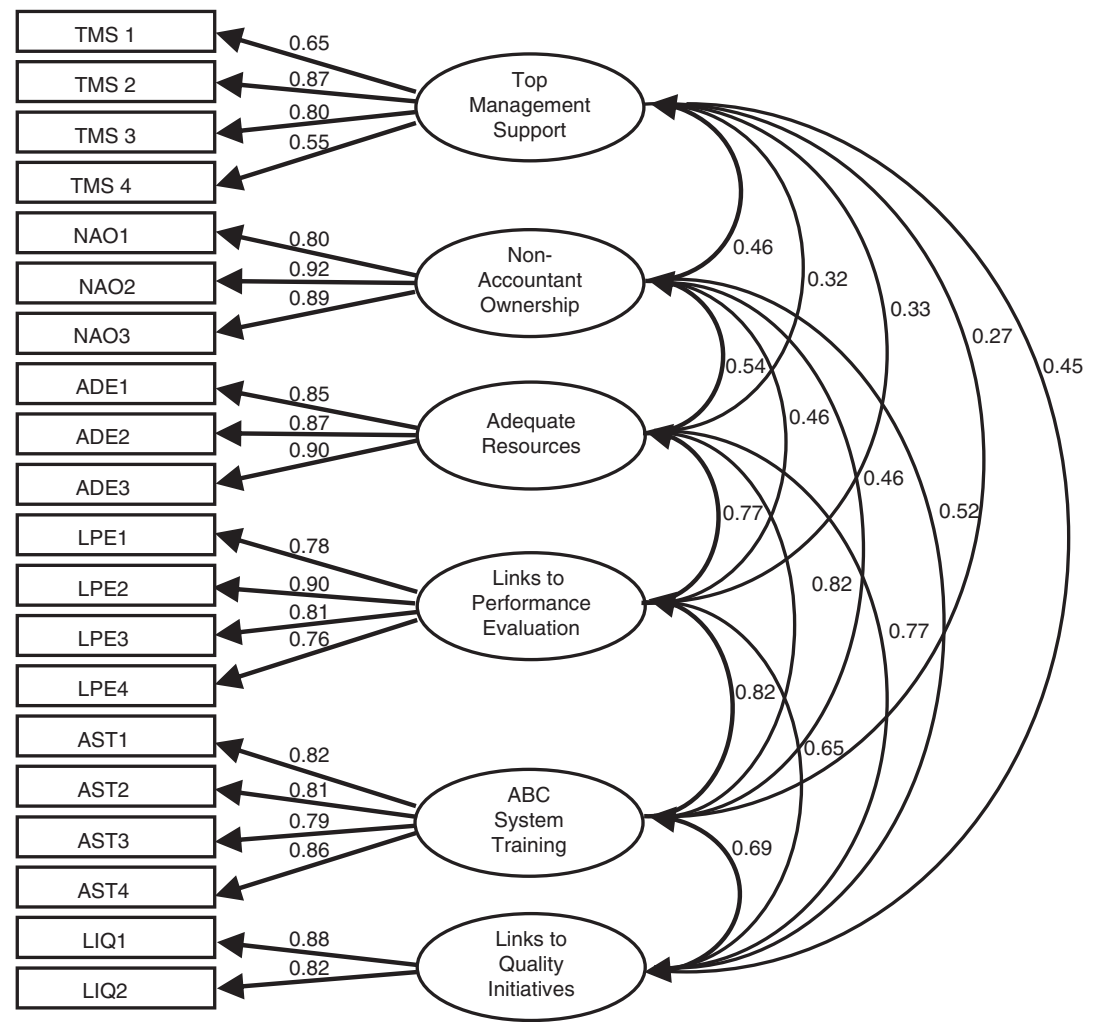

Notes: $p$-value $=0.265, \mathrm{CMIN} / \mathrm{df}=1.017, \mathrm{AGFI}=0.83, \mathrm{CFI}=0.99, \mathrm{NFI}=0.90, \mathrm{IFI}=0.99$, $\mathrm{RMR}=0.026$, and RMSEA $=0.026$
ISO 9000 certified companies in Thailand 297

Figure 2.

$\mathrm{CFA}$ of $\mathrm{ABC}$ implementation success of ISO 9000 certified companies in Thailand

normally more than half of the variance is captured by the six constructs of this study (Thoumrungroje and Racela, 2013). In summary, the construct reliability was acceptable. These results are presented in Table II, which shows item and construct reliability, scale item scores and aggregated score for each latent construct.

To assess discriminant validity, correlations among the constructs were investigated. As shown in Table III, all correlations are below the $r=0.85$ cut-off suggested by Brown

\begin{tabular}{lcccccccr}
\hline Construct & Mean & SD & TMS & NAO & ADE & LPE & AST & LIQ \\
\hline TMS & 4.22 & 0.52 & - & & & & & \\
NAO & 3.82 & 0.73 & $0.383^{* *}$ & - & & & & \\
ADE & 3.80 & 0.64 & $0.303^{* *}$ & $0.489^{* *}$ & - & & & \\
LPE & 3.59 & 0.73 & $0.250^{* *}$ & $0.403^{* *}$ & $0.661^{* *}$ & - & & \\
AST & 3.82 & 0.61 & $0.237^{*}$ & $0.418^{* *}$ & $0.749^{* *}$ & $0.707^{* *}$ & - & \\
LIQ & 3.81 & 0.66 & $0.386^{* *}$ & $0.422^{* *}$ & $0.676^{* *}$ & $564^{* *}$ & $0.610^{* *}$ & -
\end{tabular}

Notes: TMS, top management support; NAO, non-accounting ownership; ADE, adequate resource; LPE, link to performance evaluation; AST, ABC system training; LIQ, link to quality initiative. $* * p<0.01 ; * p<0.05$

Table III.

Construct correlation matrix 
ARA

22,3

298
(2006) and therefore the discriminant validity is established. Moreover, Table III shows significant positive correlation among all variables (TMS, NAO, ADEs, LPE, AST, and LIQs).

To verify common biases that may occur from data collected from single sources or self-reported measures, Harman's one factor test was performed. All the items of the TMS, NAO, ADE, LPE, AST, and LIQ constructs were entered into the exploratory factor analysis. The results showed that no single factor appeared from the analysis and no common factor accounts for the majority of variance in these variables, as the largest factor explains only 33.2 percent of the total variance and hence common method bias does not seem to be a problem in this paper.

The model examined here included six latent constructs, on which 20 observed variables were hypothesized to load. This is shown in Figure 2. According to the empirically supported Shields (1995) and Chongruksut and Brooks (2005) models, underlying the $\mathrm{ABC}$ success are six separate yet correlated factors. The six factors of TMS, NAO, ADEs, LPE, AST, and LIQs were correlated and all error terms were uncorrelated. The results of the CFA indicated the model fits the six constructs for the 102 participants. The $\chi^{2}$ value of 0.265 is above the suggested threshold level of 0.05 (Diamantopoulos and Siguawl, 2000). Similarly, the CMIN/df of 1.017 indicated an acceptable model fit. The observed RMR and RMSEA of 0.026 and the AGFI is 0.83 suggested a good fit of these data to the model, as did the CFI of 0.993, the NFI of 0.903 , and the IFI of 0.993 . These values are above the recommended threshold level of 0.90. In summary, the overall fit supported the model. Based on the results of the CFA, the success of $\mathrm{ABC}$ implementation in the context of ISO 9000 certified companies in Thailand is accounted for by the six constructs (TMS, links to performance measures, ADEs, AST, LIQs, and NAO). This model confirms the research of Shields (1995) and Chongruksut and Brooks (2005) and is useful for companies with a focus on quality, such as ISO 9000 certified companies that have decided to use the $\mathrm{ABC}$ system.

\section{Discussion and conclusion}

The purpose of this study is to examine the success of $\mathrm{ABC}$ implementation by CFA of ISO 9000 certified companies in Thailand. The work contributes to the body of work investigating contextual and behavioral factors influencing $\mathrm{ABC}$ implementation success. The researcher collected data from a survey of accountant managers from 102 firms with ISO 9000 certified status in Thailand and the results of CFA confirmed the model fitted for the six constructs; behavioral and organizational constructs (TMS, AST, NAO, LIQs, ADEs, and LPE) affect the success of ABC for ISO 9000 certified companies in Thailand.

TMS is the most important factor in building success in $\mathrm{ABC}$ implementation and this is consistent with Chongruksut and Brooks (2005), who ranked factors influencing $\mathrm{ABC}$ implementation success in Thailand. They asserted that TMS is critical for ABC implementation success. Hence, for firms adopting, implementing, and using $\mathrm{ABC}$, management teams must have clear objectives and a commitment to $\mathrm{ABC}$ information dissemination in order to achieve $\mathrm{ABC}$ implementation success. Based on the factor loading of TMS, senior management should focus on providing visible support for $\mathrm{ABC}$ initiatives, such as exercising its authority in support of $\mathrm{ABC}$. Management should also communicate its support for $\mathrm{ABC}$ systems and highlight its objectives. Prior research has found that national culture had a relationship with $\mathrm{ABC}$ as shown by Hofstede (1976), who divided national culture into five dimensions (power distance, individualism, uncertainty avoidance, masculinity, and Confucian dynamism). In addition, 
Brewer (1998) showed that national cultures with a high power distance had higher level of success than countries with low power distance, which is consistent with this research; Thailand has the former type of culture. The level of command and the power of the management are also somewhat prominent so if an $\mathrm{ABC}$ project originates with a top-level manager, the chance of success is high because subordinates in a high power distance culture will be comfortable with the "top-down" approach. However, contentious issues may arise about the level of support from the administration, although the $\mathrm{ABC}$ project management may fully support subordinates committed to using costing systems as a means of achieving their goals. That said, top-down commands can cause subordinates discomfort and therefore the support of senior management should be at an appropriate level. That is, the executive should have a role in the initiation and adoption stage, and for the rest, including adaptation, acceptance, routinization, and the infusion stage, management should play the role of providing opportunities for personal and team operations to function as defined.

AST is an important determinant in reducing resistance to the $\mathrm{ABC}$ team and in improving knowledge of $\mathrm{ABC}$ among employees. If $\mathrm{ABC}$ staff are knowledgeable, a higher degree of ABC success is likely, and this is consistent with Shields (1995), Krumwiede (1998), and Majid and Sulaiman (2008) who stated that training is a key factor in enhancing $\mathrm{ABC}$ success. $\mathrm{ABC}$ training can build strong teams and this is associated with the perceived significance of the task and development of the $\mathrm{ABC}$ model (Anderson et al., 2002). Training in ABC systems consists of readings, lectures, on the job training, and learning from others how $\mathrm{ABC}$ works (Chongruksut and Brooks, 2005). Based on the factor loading of AST, firms with ABC implementation provide not only adequate training for the design, implementation, and use states of $\mathrm{ABC}$, but also training which is useful and appropriate. Nevertheless, the cause of high training in ISO 9000 companies in Thailand may be that Thai society is a high uncertainty avoidance culture, and employees may want more training to reduce perceived threats.

$\mathrm{NAO}$ represents the level of participation with the $\mathrm{ABC}$ project of groups and individuals in the company. As mentioned earlier, $\mathrm{ABC}$ is not only a project for accountants; it also requires the cooperation of all staff. The results of this research are consistent with Maelah and Ibraim (2006), who stated that when non-accountants participate in the early stages of $\mathrm{ABC}$ implementation, $\mathrm{ABC}$ projects are more successful. According to factor loading of NAO, firms decided to adopt and implement $\mathrm{ABC}$. ABC staff should work cross-functionally and accountants should share the ownership of information with non-accountants. In addition, training and meetings should occur among $\mathrm{ABC}$ staff to help achieve the sharing of information between $\mathrm{ABC}$ employees.

LIQs shows organizational emphasis on quality, which is important to companies' competitive advantage. If businesses integrate $\mathrm{ABC}$ systems with quality initiatives, such as TQM, just-in-time and other speed initiatives, the success of ABC is more likely. This is similar to Shields (1995), Krumwiede (1998), and Baird et al. (2007) who stated that LIQs are important for management tools, such as the $\mathrm{ABC}$ system. If $\mathrm{ABC}$ information supports quality initiatives, the usefulness of $\mathrm{ABC}$ will be clear and therefore it will contribute to $\mathrm{ABC}$ success. Moreover, when quality initiatives have been adopted, work processes are improved so if firms also launch an $\mathrm{ABC}$ project, it is more likely to succeed. In summary, firms which have quality initiatives should adopt $\mathrm{ABC}$.

$\mathrm{ADEs}$ for the $\mathrm{ABC}$ system are essential because this can build employee satisfaction, which leads to commitment, attendance, and success. Moreover, internal 
ARA

22,3

300 resources reduces restrictions on workers when the company initializes an $\mathrm{ABC}$ project. Shields (1995), Baird et al. (2007), and Chongruksut and Brooks (2005) stated that ADEs encompass the time and commitment of management, accountants, and operating employees. In addition, Majid and Sulaiman (2008) argued that personal education, specifically in the use of $\mathrm{ABC}$ software, external consultants, and training should be considered. According to the factor loading of $\mathrm{ADE}$, companies which adopt the $\mathrm{ABC}$ model should provide equipment, material, staff, and information in order to gain the ensure $\mathrm{ABC}$ implementation success.

LPE represents the degree of the company's commitment to the $\mathrm{ABC}$ system, which is measured by their use of $\mathrm{ABC}$ data in decision making. This is a result of staff conduct, which is related to how their performance is evaluated and rewarded and this increases the probability of ABC success. Shields (1995) and Anderson and Young (1999) stated that evaluation and compensation link directly to information from ABC systems, which increases the probability of activity management success. Based on factor loading, companies aiming to adopt $\mathrm{ABC}$ should design and link $\mathrm{ABC}$ information to the evaluation and compensation of all workers.

The CFA discussed in this paper demonstrates the fit of the six-factor explanation of the $\mathrm{ABC}$ implementation success. In terms of content and construct validity, reconfirmation of the five factors of Shield's (1995) model and the one recommendation of Chongruksut and Brooks (2005) correspond with each of the six components of the $\mathrm{ABC}$ implementation success discussed here. The factors in the $\mathrm{ABC}$ implementation success interrelate, again reflecting the theoretical association among the related components of $\mathrm{ABC}$ implementation success. Hence, the robust six factor structures of the $\mathrm{ABC}$ implementation success shows that each of the components constitutes viable independent subscales. The present study relied solely on self-reported measures and therefore a particularly salient area for future examination would be to investigate $\mathrm{ABC}$ success through mixed methods such as in-depth interviews. Additionally, much research, including this paper, has found that TMS is the most influential factor in ABC implementation and thus future research ought to continue this line of inquiry, both directly and indirectly. Future research should also investigate the relationship between all six variables in order to understand their role in successful $\mathrm{ABC}$ implementation.

\section{References}

Amir, A.M. (2011), "The indirect effects of PMS design on Malaysian service firms' characteristics and performance", Asian Review of Accounting, Vol. 19 No. 1, pp. 31-49.

Anderson, S. (1995), "A framework for assessing cost management system changes: the case of activity based costing implementation at General Motors", Journal of Management Accounting Research, Vol. 7, pp 1-51.

Anderson, S.W. and Young, S.M. (1999), "The impact of contextual and process factors on the evaluation of activity-based costing systems", Accounting, Organizations and Society, Vol. 24, pp. 525-559.

Anderson, S.W., Hesford, J.W. and Young, S.M. (2002), "Factors influencing the performance of activity based costing teams: a field study of $\mathrm{ABC}$ model development time in the automobile industry", Accounting, Organizations and Society, Vol. 27 No. 3, pp. 195-211.

Armstrong, J.S. and Overton, T.S. (1997), "Estimating non-response bias in mail surveys”, Journal of Marketing Research, Vol. 14, pp. 396-402.

Bagozzi, R.P. and Yi, Y. (2001), "On the evaluation of structural equation models", Journal of the Academy of Marketing Science, Vol. 16, pp. 74-97. 
Baird, K.M., Harrison, G.L. and Reeve, R.C. (2004), "Adoption of activity management practices: a note on the extent of adoption and the influence of organizational and culture factors", Management Accounting Research, Vol. 15 No. 4, pp. 383-399.

Baird, K., Harrison, G. and Reeve, R. (2007), "Success of activity management practices: the influence of organization and cultural factors", Accounting and Finance, Vol. 47 No. 1, pp. 47-67.

Banker, R.D., Bardhan, I.R. and Chen, T.Y. (2008), "The role of manufacturing practices in mediating the impact of activity-based costing on plant performance", Accounting, Organizations and Society, Vol. 33, pp. 1-19.

Bhuiyan, N. and Alam, N. (2005), "An investigation into issues related to the latest version of ISO 9000”, Total Quality Management, Vol. 16 No. 2, pp. 199-213.

Brack, K. (1999), “Qualified gains”, Industrial Distribution, Vol. 88 No. 1, pp. 52-54.

Brewer, P.C. (1998), "National culture and activity-based costing systems: a note", Management Accounting Research, Vol. 9 No. 2, pp. 241-260.

Brimson, J. and Antos, J. (2004), "Predictive accounting", Journal of Corporate Accounting and Finance, Vol. 15 No. 3, pp. 61-69.

Brown, T.A. (2006), Confirmatory Factor Analysis of Applied Research, Guilford Press, New York, NY.

Bryne, B.M. (2001), Structural Equation Modeling with AMOS, Lawrence Erlbaum Associates, Mahwah, NJ.

Byrne, S. (2011), "What determines ABC success in mature sites?", Journal of Accounting \& Organizational Change, Vol. 7, pp. 259-277.

Cagwin, D. and Bouwman, M.J. (2002), "The association between activity-based costing and improvement in financial performance", Management Accounting Research, Vol. 13, pp. 1-39.

Chin, K.W., Poon, G.K.K. and Pun, K.F. (2000), “The critical maintenance issues of the ISO 9000 system: Hong Kong manufacturing industries' perspective”, Work Study, Vol. 49 No. 3, pp. 89-96.

Chongruksut, W. and Brooks, A. (2005), "The adoption and implementation of activity-based costing in Thailand", Asian Review of Accounting, Vol. 13 No. 2, pp. 1-17.

Cooper, R., Kaplan, R.S., Maisel, L.S., Morrissey, E. and Oehm, R.M. (1992), Implementing Activity-Based Cost Management: Moving from Analysis to Action, Institute of Management Accountants, Montvale, NJ.

Diamantopoulos, A. and Siguawl, J.A. (2000), Introduction LISREL: A Guide for the Uninitiated, Sage Publication, London.

Foong, S.F. and Teruki, N.A. (2009), "Cost-system functionality and the performance of the Malaysian palm oil industry", Asian Review of Accounting, Vol. 17 No. 3, pp. 212-225.

Foster, G. and Swenson, D.W. (1997), "Measuring the success of activity-based cost management and its determinants", Journal of Management Accounting Research, Vol. 9, pp. 109-142.

Goodman, D. (1998), "Earning the ISO 9000 seal of approval”, World Trade, Vol. 11 No. 9, pp. 46-49.

Gosselin, M. (1997), "The effect of strategy and organizational structure on the adoption and implementation of activity-based costing", Accounting, Organizations and Society, Vol. 22 No. 2, pp. 105-122.

Hofstede, G.J. (1976), "Nationality and espoused values of managers", Journal of Applied Psychology, Vol. 61, pp. 148-155.

Innes, J., Mitchell, F. and Sinclair, D. (2000), "Activity-based costing in the UK.'s largest companies: a comparison of 1994 and 1999 survey results", Management Accounting Research, Vol. 11, pp. 349-362. 
ARA

22,3

302
Ittner, C.D., Lanen, W.N. and Larcker, D.F. (2002), "The association between activity-based costing and manufacturing performance", Journal of Accounting Research, Vol. 40 No. 3, pp. 711-726.

Kennedy, T. and Affleck-Graves, J. (2001), "The impact of activity-based costing techniques on firm performance", Journal of Management Accounting Research, Vol. 13, pp. 19-39.

Krumwiede, K.R. (1998), "The implementation stages of activity-based costing and the impact of contextual and organizational factors", Journal of Management Accounting Research, Vol. 10, pp. 239-277.

Larson, P.D. and Kerr, S.G. (2002), "ISO and ABC: complements or competitors?", The International Journal of Logistics Management, Vol. 13 No. 2, pp 91-100.

Larson, P.D. and Kerr, S.G. (2007), "Integration of process management tools to support TQM implementation: ISO 9000 and activity-based costing", Total Quality Management, Vol. 18, pp. 201-207.

McDonald, M., Mors, T. and Phillips, A. (2003), "Management system integration: can it be done?”, Quality Progress, Vol. 36 No. 1, pp. 67-74.

McGowan, A.S. and Klammer, T.P. (1997), "Satisfaction with activity based costing management implementation", Journal of Management Accounting Research, Vol. 9, pp. 217-237.

Maelah, R. and Ibrahim, D.N. (2006), "Activity-based costing (ABC): Adoption among manufacturing organizations - the case of Malaysia", International Journal of Business and Society, Vol. 7 No. 1, pp. 70-101.

Maiga, A.S. and Jacobs, F.A. (2008), "Extent of ABC use and its consequences", Contemporary Accounting Research, Vol. 25 No. 2, pp. 566-593.

Majid, J.A. and Sulaiman, M. (2008), "Implementation of activity based costing in Malaysia: a case study of two companies", Asian Review of Accounting, Vol. 16 No. 1, pp. 39-55.

Morakul, S. and Wu, F.H. (2001), "Cultural influences on the ABC implementation in Thailand's environment", Journal of Managerial Psychology, Vol. 16 No. 2, pp. 142-156.

Nunnally, J.C. and Bernstein, I.H. (1994), Psychometric Theory, McGraw-Hill, New York, NY.

Roberts, M.W. and Silvester, K.J. (1996), "Why ABC failed and how it may yet succeed", The Journal of Cost Management, Winter, pp. 23-35.

Santos, L. and Escanciano, C. (2002), "Benefits of ISO 9000:1994 system”, International Journal of Quality \& Reliability Management, Vol. 19 No. 3, pp. 321-344.

Sayle, A.J. (2005), “Opportunities are everywhere”, Quality Progress, Vol. 38 No. 4, pp. 33-38.

Schick, A.G., Gorden, L.A. and Haka, S. (1990), "Information overload: a temporal approach", Accounting Organizations and Society, Vol. 15, pp. 199-220.

Shields, M.D. (1995), "An empirical analysis of firms' implementation experiences with activity-based costing", Journal of Management Accounting Research, Vol. 7, pp. 148-166.

Shields, M.D. and Young, S.M. (1989), "A behavioural model for implementing cost management systems”, Journal of Cost Management, Vol. 3, pp 17-27.

Shields, M.D. and McEwen, M.A. (1996), "Implementing activity-based costing systems successfully", Cost Management, Vol. 9 No. 4, pp. 15-22.

Smith, M. (2003), Research Methods in Accounting, Sage, London.

Smit, M., Abdullah, Z. and Abdul-Razak, R. (2008), "The diffusion of technological and management accounting innovation: Malaysian evidence”, Asian Review of Accounting, Vol. 16 No. 3, pp. 197-218.

Swenson, D. (1995), "The benefits of activity-based cost management to the manufacturing industry", Journal of Management Accounting Research, Vol. 7, Fall, pp. 167-180. 
Thoumrungroje, A. and Racela, O. (2013), "The contingent role of customer orientation and entrepreneurial orientation on product innovation and performance", Journal of Strategic Marketing, Vol. 21 No. 2, pp. 140-159.

Tupmongkol, T. (2008), "An empirical study of the factors of the activity-based costing (ABC) implementation in Thailand: four case studies in Thai state enterprises (TSEs)", unpublished Doctoral, Northumbria University, Newcastle upon Tyne.

\section{ISO 9000 certified companies in Thailand}

303

\section{Further reading}

Abdul Majid, J. and Sulaiman, M. (2008), "Implementation of activity based costing in Malaysia", Asian Review of Accounting, Vol. 16 No. 1, pp. 39-54.

Leticia, S. and Escanciano, C. (2002), "Benefits of the ISO 9000:1994 system: some considerations to reinforce competitive advantage", International Journal of Quality \& Reliability Management, Vol. 19 No. 3, pp. 321-344.

Thai Industrial Standard Institute (2012), "List of certified companies in Thailand: ISO 9000", available at: http://app.tisi.go.th/syscer/9000.html (accessed September 1, 2012).

To purchase reprints of this article please e-mail: reprints@emeraldinsight.com Or visit our web site for further details: www.emeraldinsight.com/reprints 